AperTO - Archivio Istituzionale Open Access dell'Università di Torino

\title{
Cultural heritage in a changing world
}

\section{This is a pre print version of the following article:}

Original Citation:

Availability:

This version is available http://hdl.handle.net/2318/1666927

since 2018-04-25T00:34:07Z

Published version:

DOI:10.1007/s10824-017-9301-5

Terms of use:

Open Access

Anyone can freely access the full text of works made available as "Open Access". Works made available under a Creative Commons license can be used according to the terms and conditions of said license. Use of all other works requires consent of the right holder (author or publisher) if not exempted from copyright protection by the applicable law. 


\section{BOOK REVIEW}

\section{Enrico Bertacchini*}

\section{Cultural Heritage in a Changing World}

The book Cultural Heritage in a Changing World contains a series of essays that address from several perspectives the evolving nature of cultural heritage due to the social, economic and technological changes occurring at the dawn of the $21^{\text {st }}$ century. The work is one of the outputs of the research project RICHES (Renewal, Innovation and Change: Heritage and European Society) funded by the European Commission under the $7^{\text {th }}$ Framework Programme. As a result, the collection of essays reflects the complexity and heterogeneity of the work packages included in the research project, as well as a multiplicity of contributions, ranging from case study reports to analyses addressing more general trends. Yet, the editors have made an admirable attempt to organize and structure the collection in such a way it guides the reader to appreciate different dimensions of change in the cultural heritage domain and their inherent challenges.

As proposed by the editors in the introductory chapter, two main trends permeate the entire work. Firstly, the "decentring" of culture and cultural heritage away from institutional structures towards the individual. Secondly, the change due to the pervasive influence of digital technologies in the production, access to and use of cultural resources. These two dimensions are strictly intertwined and often difficult to disentangle in the essays, but their implication is quite clear. These changes are likely to enable new organizational arrangements to enhance individual and collective cultural participation as well as new forms of experiencing cultural heritage. At the same time, traditional cultural institutions face opportunities, but also challenges, to revitalize their role as stewards of cultural heritage by adapting to the new individual-centered and digital-oriented scenario.

The book is divided into four parts. The first one, entitled "Context of Change", introduces some of the key issues and themes relevant to understand the main transformations occurring to cultural heritage. The first chapter by Mariella Combi explores from a cultural anthropology perspective how the diffusion of communication technologies have triggered cultural changes, with a particular focus on the contemporary emergence of "digital natives". This subject may be arguably deemed as a prerequisite to better contextualize the current evolution in the conceptualization of cultural heritage.

The other chapters of this part broadly covers three additional issues. The first one refers to accessibility to cultural heritage. The chapter by Calamai, Ginouvès and Bertinetto presents evidence concerning the potential of making accessible intangible cultural heritage through digital audio archives. Similarly, the essay by Guccio, Martorana, Mazza and Rizzo inquires whether and how the digitization and ICTs influence the access to Italian public historical archives. Although the evidence does not allow the authors to draw clear-cut conclusions on this point, their economic approach and interpretative framework can be particularly useful for scholars studying access to digital collections in other cultural domains.

A second theme, connected to that of accessibility, concerns the challenges posed by the management of intellectual property rights for the re-use of digital cultural collections. In this case, the chapter by Truyen and Waelde is particularly illustrative of the legal complexities that the

\footnotetext{
* Department of Economics and Statistics "Cognetti De Martiis”, University of Torino. 
European copyright law framework sets to the access to and re-use of digitized photography of cultural heritage items. The fact that similar concerns are also discussed in the abovementioned chapter on digital audio archives points out the complexity to adapt legal institutions to the new context led by digital technologies.

The opportunities deriving from interdisciplinary collaborations between arts and new technologies is the third dimension of change and is the focus of Whatley and Subiescu's chapter. By presenting the case of digital dance and performance, the authors set an intriguing exploration on how artistic expressions today increasingly emerge from the confluence of different fields of practices and techniques. As these new artistic products are likely to constitute part of the future cultural capital, this contribution implicitly suggests new ways of conceptualizing heritage.

The second section of the book, with the title "Mediated and Unmediated Heritage", focuses on the very relevant issue of how digital technologies are reshaping the authority over the selection, definition, curation and interpretation of heritage. The contributions of this section illustrate experiences or proposals to make cultural institutions cope with the emerging digital practices of designation and contextualization of heritage-related knowledge by individuals and communities. In this context, Marras, Messina, Mureddu and Romoli reflect on a case study of the project undertaken by the National Archeological Museum of Cagliari to facilitate adaptation and renewal of exhibitions and visitors' engagement through a series of digital tools with the overall aim to make the institution more inclusive. In turn, Navarrete and Owen emphasize in their essay how digital technologies have magnified heritage objects as information carriers, making museums virtual information spaces. Of particular relevance in this case is the use of metadata for the digitized heritage entries. This technical subtlety is of paramount importance to manage the large amount of digitized information that museums store and produce and has also crucial implication for the interpretation of digitized heritage items by digital users and communities. On a similar line of reasoning, the chapter by Aydin and Schnabel makes a conceptual proposal to apply videogames and gamification strategies to make museums fully exploit the advantages of digital interpretation and dissemination of cultural heritage information. As widespread medium of contemporary societies, digital and video-games have the potential to deeply influence the way in which individuals and communities perceive and experience heritage goods.

Very connected to the issue of unmediated heritage, the section of the book dedicated to cocreation, living heritage and social cohesion is perhaps the most heterogeneous one, but equally inspiring to vividly grasp the factors and practices that are transforming the conceptualization of cultural heritage. Except for the essay by Taylor and Knefsey, which is the only one directly addressing the evolution a urban living heritage (the London's Notting Hill Carnival), the other chapters focus on the interplay between digital technologies and community practices to foster the role of cultural heritage in contemporary multicultural societies as a driver for social cohesion and inclusion. Reporting on the project "Eurovision - Museums Exhibiting Europe" Shilling's chapter stresses the need for local and regional European museums to broaden national perspectives on heritage and develop a cross-cultural European vision. How to adapt and personalize individuals' experience through digital technologies to enhance public engagement in cultural heritage is the focus of the chapter by de los Rios Peres, Cabrera-Umpierrez, Arredondo, Jiang, Floch and Beltran. They report on the pilot project for a set of cloud-based digital solutions, which allow visitors to cultural places to personalize their experience using information according to their interests and to contribute to the digital storytelling of the experienced cultural heritage. The positive view concerning the potential of digital technologies in enhancing public engagement in cultural heritage 
is softened by the contribution of Dora Constantinidis. By presenting the experience of a project related to crowdsourcing the digital preservation of Afghan heritage, she illustrates the challenges that go beyond the mere adoption of new technologies, such as the relevance of identifying proper engagement strategies and change agents in a community, based on the accurate analysis of the social and political context. Further, Popple and Mutibwa's contribution raises another crucial issue characterizing the use of digital technologies for co-creation methods in the cultural heritage field. Reporting on the experience of a UK project to create a participatory storytelling tool involving communities and cultural institutions, the authors highlight how the success of projects based on community engagement is strongly linked to the proper design of open access models for the digital tools as well as the content created and shared by community members.

The last part dedicated to the effect that digital technologies have on identity and belonging is perhaps the less developed content of the book, albeit these two notions are particularly relevant for the evolving definition of cultural heritage. In addition, the two chapters of this section cover very diverse subjects. The former essay by Boccanegra Barbecho and Toscano analyzes how the memory of the Spanish Republican exile has evolved in the digital domain. The latter is a personal account by the chinese artist Situ Xiaochun about how new technologies have impacted social practices, artists' work and the awareness of cultural heritage in China.

In summary, Cultural Heritage in a Changing World contributes to deepen and expand the debate about the current evolution of the role of cultural heritage in societies on several directions.

Although not providing a fully-fledged economic analytical perspective, it is a book that cultural economists can find inspirational and full of insights worth to be incorporated into their analytical tools. It is commonly recognized that one of the main challenges in conceptualizing cultural heritage under an economic perspective is that heritage is per se a social construction and the supply and demand of this very peculiar class of goods depends on the interaction of cultural and economic values. The many cases and projects documented in the book show how different forces and factors, by shaping new ways in which heritage goods are made accessible and experienced, are enriching the cultural values conveyed by heritage. At the same time, digital technologies are unlocking the public good nature of the knowledge and information connected to heritage, that was traditionally embedded in rival and excludable services by museums and heritage institutions. Further, the new possibilities provided by digital technologies to investigate the role of cultural heritage in building up collective identities might somehow inspire cultural economics research incorporating the recent theoretical and empirical developments of identity economics.

Though, addressing the radical changes occurring through digital technologies in the cultural heritage domain, the collection of essays mainly focuses on projects or case studies that are less renowned to the general public. While this may be a deliberate choice of perspective, the book seems to not address some relevant experiences in this field undertaken by new players, such as Wikimedia Foundation or Google, and leaves on the background some global challenges such as that of the emerging role of technological providers as new gatekeepers of information and knowledge related to digitized cultural heritage.

In fact, albeit the overarching title, it should be noted that the book primarily provides a European perspective to the changes occurring in the cultural heritage domain. Although this can be seen as a potential limitation, it does not impair the intellectual effort of the editors and authors if their work is properly contextualized by the readership within the current European cultural policy debate. At the same time, given the pervasive and rapid adoption of digital technologies worldwide, much of 
Book review published in Journal of Cultural Economics 41 (3), 337-340

the reflections and findings presented in this book can be useful for cultural heritage practitioners and scholars in other parts of the world. 